\title{
Early Intervention in Vietnam
}

\section{Marja Hodes}

This essay describes the setting up of early intervention services in Vietnam. From the outset, there was a focus on developing staff training programmes alongside establishing model early intervention programmes to ensure that the work would be sustained at the end of the project funding and spread throughout the country. The success of this work has now led to the government of Vietnam wanting to move to the next stage and to begin to develop training for full inclusion of children with disabilities in the school system.

Up until 1998, I spent a lot of time travelling with my husband through many developing countries. Often we ended up somewhere visiting an institute for children with an intellectual disability, just to see what they were doing for these children. Sometimes, we would meet a nice young man or woman with Down syndrome and have a chat with him/her and his/her family. Both working as educational psychologists in the field of intellectual disabilities, we decided that we would like to live for a longer period abroad to contribute to the development of children with an intellectual disability and their families.

In 1998 we got the chance. The Vietnamese government wanted to set up a faculty for special education for children with an intellectual disability at the University of Ha Noi. We had previously travelled through Vietnam in 1994. We loved the country and the people. My husband applied for the job and was appointed. At that time I was working in The Netherlands as an early intervention specialist. We had just finished a big national research project on early intervention. Although not involved as a Committee member, I was already working with Stichting Downsyndroom (the Dutch Down Syndrome Foundation). I was very enthusiastic about early intervention services, especially about working together with parents and families in a real partnership. I wondered if I could set up early intervention services in Vietnam as well.

\section{First orientation}

In the beginning of 1998 we went to Vietnam for six weeks to prepare for our work. Our son of 15 months of age accompanied

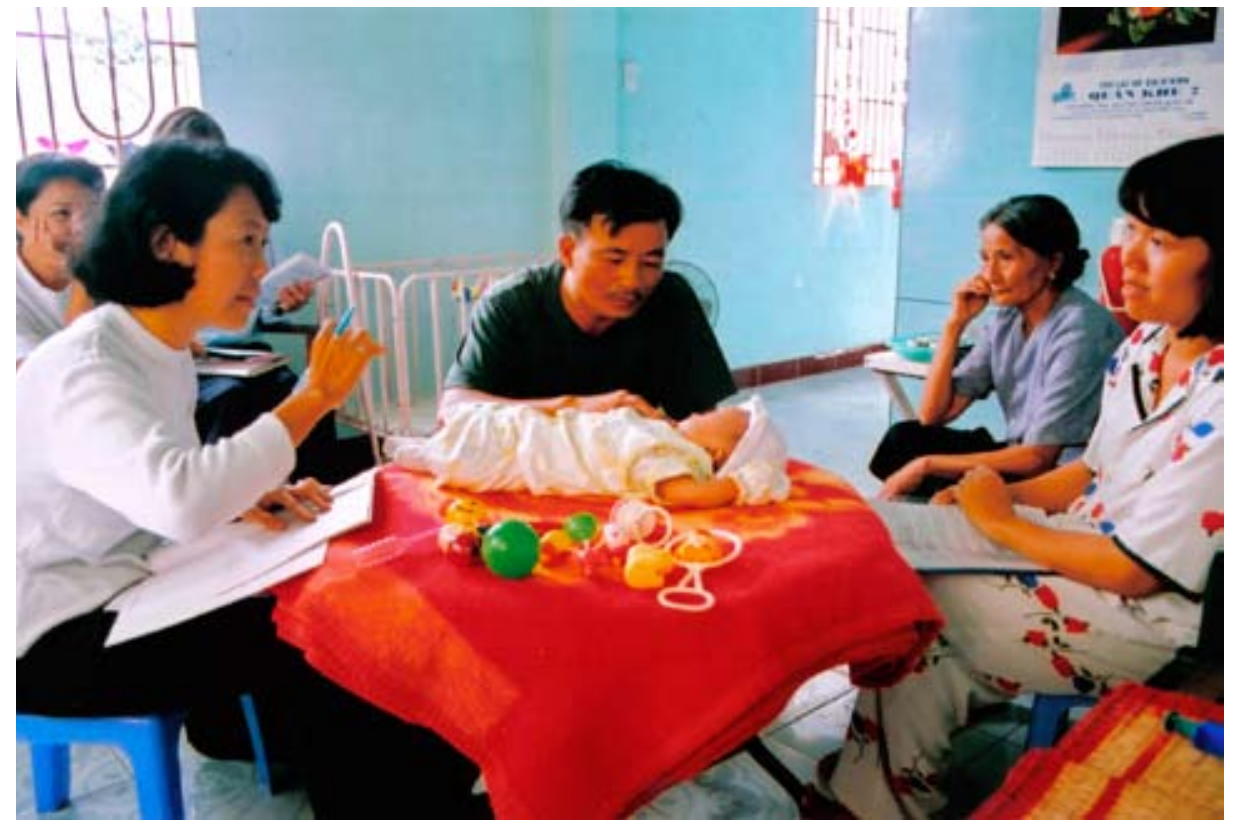

us. For me it was important to find out if wealthy family, the family was able to pay he was able to cope with the (hot) weather for medical service and treatment. Howin Vietnam before actually moving there. ever, if the same child was born into a less During our first visit it was clear that wealthy family then medical support was there was a great need for early interven- too unaffordable. It still happens that chiltion for children with an intellectual disa- dren with Down syndrome die because of bility and their families. We visited several a lack of medical treatment. In poor famifamilies with a child with special needs, lies a disabled child more often than not including some with Down syndrome. is a burden for the entire family. This is None of these children went to school. particularly so when the child is not able Nor were they accepted at kindergartens. to contribute to the daily bowl of rice. In There was no choice but for the children these circumstances, neglect can become to stay at home without any education or a problem. support. In Vietnam, a child usually goes to primary school at the age of six years. But children with Down syndrome were not admitted to primary schools. There were a few special schools and, if you were lucky, you might be offered a place in one. For the majority of the children this was not an option.

Also the families themselves were facing difficulties. Where a child was born into a
Further adding to these challenges, the families often have to deal with a lot of the myths around the cause of an intellectual disability such as Down syndrome. Nearly every family feels very much ashamed having a child with a disability. We were told several popular 'explanations' for why a child with Down syndrome might be born. These included evil spirits, quarrels between spouses, punishment 
because of doing something wrong and infection from another person with Down syndrome. For this last myth, we offered a wonderful counterexample: At several schools, the teachers were very impressed that my husband and I had been working for many years with children with Down syndrome and yet had a healthy son! Knowledge of the real causes of intellectual disability was, and still is, very poor.

During that first visit, it became clear to me that setting up early intervention and pre-school education services for children with an intellectual disability would become my task in Vietnam. Back in Holland I wrote a project proposal that was accepted. In September 1998, we left Holland and went to live and work in Ha Noi for a period of more than $2 \frac{1}{2}$ years.

\section{Setting up Early Intervention Services}

Setting up early intervention services in Vietnam was far from an easy task. There are lots of differences between working in the big cities and doing so out in the country. And although North and South Vietnam were united way back in 1975 , there still is a huge difference between working in North and South Vietnam. We chose to start in both the North and the South, more specifically in their two biggest cities: Ha Noi and Ho Chi Minh City.

Ha Noi was chosen because it is the capital of the country. The country is ruled from there. All the decisions and laws originate in Ha Noi. Ho Chi Minh City was also chosen because of its being the biggest city of the country (more than six million inhabitants). Due to the contacts with foreign countries (France) that existed in the past there is some more experience in the field of intellectual disability.

Running projects in North and South Vietnam simultaneously also gave both areas the feeling of being equally important. To implement early intervention throughout the entire country really was a must.

The projects in these cities turned into model projects. In both cities we got the support from the government. This support was very important as without it, it would be virtually impossible to achieve sustainability.

\section{Projects in $\mathrm{Ha}$ Noi}

My family and I were living in Ha Noi.
My husband was working at the Hanoi Pedagogic University. My son went to the international kindergarten. I was running two projects in Ha Noi, both related to the Ministry of Education and Training. I will describe them in more detail below.

\section{Project of the Integrated Kindergartens in Hoan Kiem District - Ha Noi}

The Ministry of Eductation and Training started a pilot-project that supports the development of early intervention and pre-school education for children with an intellectually disability at kindergarten age as a model project for the entire country.

Ha Noi was chosen as the first project place. Hoan Kiem district, the old district in the centre of $\mathrm{Ha}$ Noi, was chosen to be the first project site for an Integrated Kindergarten Program. The Education and Training Chamber of Hoan Kiem district (this Chamber is responsible for the training and education and upgrading of kindergarten teachers) was given the task to carry out this program, in close collaboration with the People's Committee of Hoan Kiem (this is the local department of the socialist party).

In Hoan Kiem District a survey was carried out to get more information about the actual prevalence and numbers of children with a disability. The regular kindergartens in this district (19) were asked to accept these children. I developed a training program 'Early Intervention and Pre-school education for Children with an intellectual disability in Kindergarten age'. All the teachers at these kindergartens (40) received an intensive training course for two consecutive years. This program provided them with working knowledge of, and experiences in, working with children with an intellectual disability, about early intervention and pre-school education for this group of children and about how to co-operate with parents and families. The teachers had to follow classes and workshops. I gave a lot of practical tuition. For example: How to do a home visit in a family, how to observe children in your classroom, how to make an IEP for the child, how to teach a child with Down syndrome, and how to make your own teaching materials. The program ran from April 1999 through April 2001. In addition to the teachers, the staff of the Educa- tion and Training chamber were trained.

The Ministry of Education and Training asked a program developer of the National Educational Channel to record all lectures and workshops and practical seminars. Three documentaries were made and broadcast across Vietnam. In these films, we paid attention to the causes of intellectual disability and to the importance of early intervention. In addition, a brochure was made and we sent out information via the sound system around the markets in several places.

At the end of this project we could offer the teachers a real Vietnamese certificate for teaching early intervention and preschool education. This was important for the teachers as it offered them more salary and the opportunity to enrol in other programs.

\section{Project on 'The development of the Early Intervention Centre for Children with an intellectual disability and their families' - Ha Noi}

During the time the first project ran, we found out that there was a lack of accurate diagnosis and assessment of children with disabilities. The teachers received children who were simply said to "have special needs" in their classroom, without knowing anything in particular about them. Furthermore, the teachers themselves had little knowledge about intellectual disabilities. Sometimes there was some medical information. But, more often than not, there was no information at all. There was no place where parents could go to get more information about what was wrong with their child and to get advice what they could do for their child.

There was a big need for a facility where parents could go with all their questions and worries and where a multi-disciplinary team would support the child and the family. Together with the Ministry of Education and Training we selected the staff for a future Parent Guidance Room. For the remainder of the period I was in Vietnam I started the training of its staff. The ministry took the responsibility to further develop the Parent Guidance Room. I initiated the training programme in March 2000 for the duration of one year.

The training program focused on psychological evaluation of young children with the suspicion of having an intellectual 
disability and on the development of early intervention services for children with an intellectual disability and their families. A small group of specialists received the training: notably psychologists, a doctor, a social worker, special teachers and some students of the Hanoi Pedagogic University. Of course this was not enough, but at least it was a first step. Several children of the kindergartens of Hoan Kiem district came with their parents and family to this room. They offered us the opportunity to learn directly from real cases.

At least the group of 'specialists' became knowledgeable about how to carry out an evaluation and how to work closely together with other disciplines, with parents and with families and how to specify a diagnosis. At the end of the project period the responsibility was handed over to the government. Unfortunately it was too difficult to take the next step. There were too much different interests from different parties. When I came back in 2003 this Parent Guidance Room was closed down.

\section{Project in Ho Chi Minh City}

\section{The development of the Early Intervention Centre for Children with an intellectual disability and their families - RECDC - Ho Chi Minh City.}

Every six weeks I went for eight days to Ho Chi Minh City, to run a project at the Research and Education Centre for Disabled Children. The Ministry of Education and Training gave the responsibility for setting up early intervention to the local authorities of Ho Chi Minh City. The Research and Education Centre for Disabled Children (RECDC) received the official task to set up early intervention. This Centre already had a longer history. It has three sections: one for blind children, one for hearing impaired children and a section for children with an intellectual disability. The last section had just started when I came to Vietnam.

The director had asked for support to set up family services. The awareness of the importance of working with families was already there. She wanted her Centre to become a 'real' Early Intervention Centre with diagnosis and assessment, centre-based and home-based early intervention and supporting activities for kindergartens and training and upgrading for teachers from special and regular kindergartens.

So, I started to develop a program to set up an Early Intervention Centre for children with an intellectual disability and their families. The entire staff of the Centre received the intensive training program. We had a lot of discussion about the importance of a multi-disciplinary team. The director of the Centre selected a wonderful group of very dedicated people: a doctor, social workers, psychologists, special teachers from the special school, and special staff were employed to become family workers.

We were able to locate some 40 families with a young child with an intellectual disability or a developmental delay. With this group of children the staff could learn the job. I gave lectures, workshops, practical seminars and a lot of training on the job (working directly with the staff with the families at the Centre, at home or at the kindergarten). Included was a big group of children with Down syndrome. The program started in November 1998 and ran until April 2001. In fact this Centre became a real example for good Early Intervention Services in Vietnam. It is very famous now and families all over the country are coming to this Centre. At this very moment the Centre is still running very well.

\section{Back in Holland}

In May 2001 we had to return to The Netherlands. We were very happy with the results that were achieved. We left good - at least in our opinion - training programs, the Early Intervention Centre in Ho Chi Minh City was well known all over the country and at the Hanoi Pedagogic University my husband had set up the section for Special education for children with an intellectual disability.

Back home, I became very disappointed about the early intervention services in The Netherlands. When I returned to my own Centre in the city of Rotterdam hardly anything was left from what was set up before I went to Vietnam. It seemed to me that the RECDC in Ho Chi Minh City was more advanced in early intervention services than what was offered then in The Netherlands. Even the old myths were back again - for example, 'the parents first need to get the chance to be parents' and 'don't bother them with early

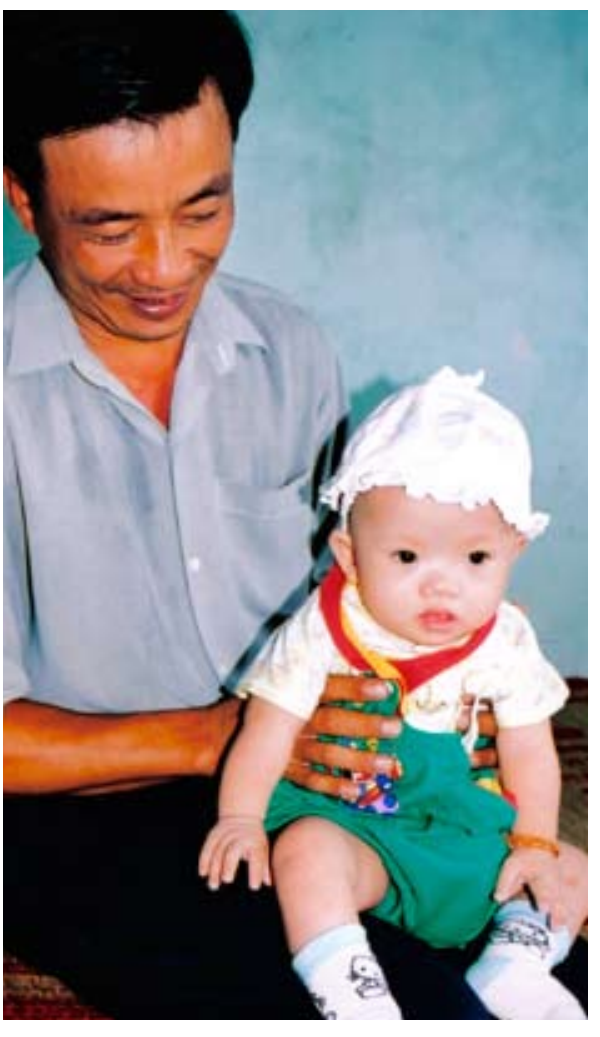

intervention'.

In that year Erik de Graaf asked me to become a member of the Committee of Stichting Downsyndroom. I agreed. After a long period of positive and fairly close co-operation I was inclined to give something back to Stichting Downsyndroom. From that moment on we had to fight very hard to re-establish early intervention in The Netherlands.

\section{Early Intervention in the Teachers Trainers Colleges}

In 2003, I received a request from the Ministry of Education and Training in Vietnam. Early intervention is part of the responsibility of this Ministry. In 2001, a 'Strategy for Educational Development 2001-2010' had been introduced. The government wanted to introduce inclusive education in kindergarten, primary and secondary schools. According to the strategy, children with mild intellectual disabilities were to become integrated within the regular educational system. Children with moderate and severe intellectual disabilities were to still enrol in special schools. Special schools were also to become special resource centres. Early intervention became an important part of this strategy towards wider inclusion. As such, the Ministry decided that early intervention should become a module in the schooling of teachers at the National 
Teachers Training Colleges. So, they asked me to write and develop a module on early intervention for children with an intellectual disability. They also asked me to teach that module at all the national colleges, i.e. one in Hanoi, one in Ho Chi Minh City and one in Nha Trang. I was very happy with this request. In the Netherlands it still is very difficult to convince the teacher trainers' colleges to include early intervention in their curriculum. And so, every half year I travelled again to Vietnam for some weeks to teach at these Colleges. In January of 2007 I finished this job. At present I am involved in writing a handbook on early intervention with a Vietnamese group of people. We hope to finish it at the end of this year.

\section{The story of Kim Anh}

In the summer of 2000, the Early Intervention Team of the RECDC phoned me about a small baby with Down syndrome. A desperate mother stood in the front gate of the Early Intervention Centre. She had a baby of a few weeks old with Down syndrome and wanted to leave her baby at the Centre. What should they do? The mother was looking for an institute which was willing to take care of her daughter Kim Anh. Her husband and mother-inlaw had asked her to find a place for the baby. Right from the delivery the family had been in shock upon learning that Kim Anh had Down syndrome. The doctors told them that they would have a child with a lot of behavioural problems, not able to look after herself, one that would never walk and never talk. The family was very much worried about the future. The father discussed with his mother what to do. Grandparents have an important role and vote in the education of the children. Her husband and family-in-law decided that Kim Anh was too much a burden for the family. It was better to find a place in an institute for her. The mother of Kim Anh was crying a lot. She understood her husband and family-in-law. But : "I'm still her mother, although she is disabled, and I love her so much..."

The team had made clear to the mother that the Centre was not an institute. They had the feeling that the mother was not willing to bring her daughter to an institute. What to do next?

Because I was living in $\mathrm{Ha}$ Noi (two hours by plane) I couldn't come immedi- ately. But via e-mail and telephone I could support them. Together we made a plan of what to do. The team had already had a lot of training in supporting parents and families. Likewise, they already had quite some knowledge about Down syndrome. So, the team had a talk with the mother. They gave her information about the possibilities of children with Down syndrome. And they offered her family support at home. The mother was very happy, but still worried that her husband and family-in-law didn't want to keep Kim Anh at home. We asked her if it would be possible that she returned together with her husband and other important family members. In doing so we could also explain to the entire family that it is important for Kim Anh to grow up in her own family. The next day the mother returned together with her husband and brother-in-law. The team had a very intensive and convincing talk with them.

Only the mother-in-law was still doubting and not able to come to the Centre.

No problem! One of the teachers was already appointed to become the family support worker. So - we prepared a meeting and the teacher went to that family. She did a great job. In the end the whole family made the decision to keep Kim Anh at home and to help her as much as they can. The family was very impressed about the work of the Centre.

Because I was giving training there every six weeks, my next visit to the Centre in Ho Chi Minh City totally centred on Kim Anh and her family. I asked the family if they were willing to support us as well. Because the team was still in training, it would be wonderful to have this family as an example. We planned to pay a home visit to the family. The whole team was very welcome in the family. I was so moved when we entered that house. Kim Anh was lying in her most beautiful clothes. The family was sitting around her, very proud. Her grandmother showed me that Kim Anh was reacting to her voice very well.

During the home visit we talked about all the possibilities a child with Down syndrome has. And we made a first estimation about all the things Kim Anh was already able to do.

The whole team was happy and proud of their work. A small baby had returned to her family!
In $2004 \mathrm{I}$ was lecturing again at the National College in Ho Chi Minh City. I contacted that same family again. The mother of Kim Anh herself is kindergarten teacher. I asked her if she would be willing to tell her story to all the kindergarten teachers. That would give them the opportunity to learn from her story, to understand parents and families better and to get convinced that children with Down syndrome have a lot of possibilities. Kim Anh was visiting the regular Kindergarten and doing very well.

Both father and mother came to the college. They took Kim Anh with them. I interviewed them about their experiences. With tears in their eyes the parents told their story. After the interview the mother showed the whole group of teachers what Kim Anh was already able to do. She sang some children's songs, recited some poems and asked her a lot of questions she could answer. The whole group of teachers was very much impressed. With a farewell song they said goodbye to Kim Anh and her family.

When we were talking about their impression a lot of teachers expressed that they became very motivated for early intervention and inclusive education. They were willing to fight to give children with Down syndrome the chance to get good and proper education. For me this was the most wonderful result of my work I could ever imagine.

Marja Hodes is an educational psychologist and president of Stichting Downsyndroom.

Correspondence to Stichting Downsyndroom . Hoogeveenseweg 38, Gebouw U 7943 KA Meppel, The Netherlands • Tel: 0522-281337 • Fax: 0522281799•E-mail: info@downsyndroom.nl·http:// www.downsyndroom.nl/

doi:10.3104/essays.2021

(C) 2007 The Author. Journal Compilation @ 2007 The Down Syndrome Educational Trust.

Received: 7 February 2007; Accepted 14 February 2007; Published online: 30 July 2007 